\title{
Eficiência térmica do coletor solar plano durante a secagem do café (Coffea arabica L.) sob diferentes condições climáticas
}

A etapa de secagem do café deve ser de forma eficiente visando sua qualidade de bebida e, a consequente competitividade do grão no mercado. Dentre as formas de secagem, pode-se adotar secador solar a fim de contornar desvantagens oriundas dos métodos convencionais. Diante dessa realidade, objetivou-se avaliar a eficiência térmica do coletor solar plano (CSP) acoplado ao secador híbrido solar elétrico (SHSE) em períodos ensolarados (PS) e com incidência de chuva (PC). A secagem do café arábica (Catuaí amarelo) foi feita no SHSE composto pelo coletor solar plano, câmara de secagem e sistema de exaustão do ar acionado por energia elétrica convencional ou fotovoltaica. 0 período efetivo de secagem solar foi de $51 \mathrm{~h} \mathrm{com}$ intermitência de $15 \mathrm{~h}$ (período noturno). Durante a secagem, monitorou-se os parâmetros de temperatura, umidade relativa (UR), irradiação solar e eíndice pluviométrico. Os frutos separados intermitência de $15 \mathrm{~h}$ (período noturno). Durante a secagem, monitorou-se os parâmetros de temperatura, umidade relativa (UR), irradiação solar e índice pluviométrico. Os frutos separados em lotes de café despolpado e natural foram acondicionados em bandejas contendo cestas removíveis no interior da câmara de secagem. A temperatura e umidade relativa média do ar ambiente foi de 23,1 oC e $76,0 \%$, respectivamente, sendo no PS de 26,4 oC e $62,0 \%$ e PC de 19,8 oC e 89,9\%. A irradiação solar e o índice de pluviosidade médio foi, respectivamente, de $210,9 \mathrm{~W} \mathrm{~m}$-2 e 10,4 mm ao longo de todo o período efetivo de secagem solar. A maior temperatura com a respectiva UR média atingida na saída do CSP ocorreu no primeiro dia do período ensolarado, sendo de 41,9 oC e 52,1\%. Observa-se maior temperatura e menor umidade relativa do ar de secagem na saída quando comparado com a entrada do coletor solar plano, independente das condições climáticas do período de secagem. A eficiência térmica média máxima obtida do CSP foi de $71,6,58,6$ e $21,3 \%$ no PS, PC e global, respectivamente. A massa de independentemente do lote e condições climáticas.

Palavras-chave: Secador híbrido solar elétrico; Parâmetros de secagem; Incidência de chuva; Perda de massa.

\section{Thermal efficiency of the flat solar collector during drying coffee (Coffea arabica L.) under different climate conditions}

\begin{abstract}
The drying stage of the coffee must be efficient, aiming at its beverage quality and the consequent competitiveness of the grain in the market. Among the forms of drying, it is possible to adopt a solar dryer in order to circumvent disadvantages arising from conventional methods. Thus, the objective was to evaluate the thermal efficiency of the flat solar collector (FSC) coupled to the hybrid electric solar dryer (HESD) in sunny periods (SP) and with incidence of rain (RP). The drying of Arabica coffee (yellow Catuai) was carried out in the HESD composed of the flat solar collector, drying chamber and air exhaust system powered by conventional or photovoltaic electric energy. The effective period of solar drying was $51 \mathrm{~h}$ with intermittence of $15 \mathrm{~h}$ (night solar collector, drying chamber and air exhaust system powered by conventional or photovoltaic electric energy. The effective period of solar drying was $51 \mathrm{~h}$ with intermittence of $15 \mathrm{~h}$ (night
time). During drying, the parameters of temperature, relative humidity (RH), solar irradiation and pluviometric index were monitored. The fruits separated in lots of pulped and natural coffee time). During drying, the parameters of temperature, relative humidity (RH), solar irradiation and pluviometric index were monitored. The fruits separated in lots of pulped and natural coffee
were placed in trays containing removable baskets inside the drying chamber. The average temperature and RH of the ambient air was 23.1 oC and $76.0 \%$, respectively, being in the SP of $26.4 \mathrm{oC}$ and $62.0 \%$ and RP of $19.8 \mathrm{oC}$ and $89.9 \%$. The average solar irradiation and pluviometric index were $210.9 \mathrm{~W} \mathrm{~m}-2$ and $10.4 \mathrm{~mm}$, respectively, throughout the effective period of solar drying. The highest temperature with the respective average $\mathrm{RH}$ reached at the exit of the $\mathrm{FSC}$ occurred on the first day of the sunny period, being $41.9 \mathrm{oC}$ and $52.1 \%$. Higher temperature and lower relative humidity of the drying air are observed at the outlet when compared to the entry of the flat solar collector, regardless of the climatic conditions of the drying period. The maximum average thermal efficiency obtained from the FSC was 71.6, 58.6 and $21.3 \%$ in the SP, RP and global, respectively. The pulped and natural fruit mass decreased by 27.4 and $34.2 \%$, respectively, due to water loss. Thus, it can be concluded that the HESD was efficient in the solar drying of coffee fruits, regardless of the lot and climatic conditions.
\end{abstract}

Keywords: Hybrid solar-electric dryer; Drying parameters; Pluviometric index; Mass loss.

Topic: Sistemas de Energia Sustentável

Reviewed anonymously in the process of blind peer.
Received: 05/10/2020

Approved: 26/11/2020
Beatriz Costalonga Vargas (iD

Universidade Federal de Viçosa, Brasil

http://lattes.cnpq.br/8731372184121178

http://orcid.org/0000-0002-2612-447X

beatriz.vargas@ufv.br

\section{Juliana Lobo Paes (iD}

Universidade Federal Rural do Rio de Janeiro, Brasil http://lattes.cnpq.br/8567579362150921

http://orcid.org/0000-0001-9301-0547

juliana.lobop@yahoo.com.br

Dhiego Santos Cordeiro da Silva (iD

Universidade Federal Rural do Rio de Janeiro, Brasil http://lattes.cnpq.br/8346916468149128

http://orcid.org/0000-0001-5368-5742

dhi_e_go@hotmail.com

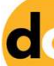

DOI: $10.6008 / C B P C 2179-6858.2020 .006 .0032$

\author{
Milena Araújo Silva (iD) \\ Universidade Federal Rural do Rio de Janeiro, Brasil \\ http://lattes.cnpq.br/6060895557867459 \\ http://orcid.org/0000-0002-4556-047X \\ milenaaraujo.silva@yahoo.com.br \\ Maxmillian Alves de Oliveira Merlo (iD) \\ Universidade Federal Rural do Rio de Janeiro, Brasil \\ http://lattes.cnpq.br/0441362832503764 \\ http://orcid.org/0000-0002-9619-4000 \\ maxmerlo2@hotmail.com \\ Pedro Luis Belfort Gomes Fernandes (iD \\ Universidade Federal Rural do Rio de Janeiro, Brasi \\ http://lattes.cnpq.br/5193050301262618 \\ http://orcid.org/0000-0003-4777-1702 \\ pedrobelfort18@gmail.com
}

Referencing this:

VARGAS, B. C.; PAES, J. L.; SILVA, D. S. C.; SILVA, M. A.; MERLO, M. A. O.; FERNANDES, P. L. B. G.. Eficiência térmica do coletor solar plano durante a secagem do café (Coffea arabica L.) sob diferentes condições climáticas. Revista Ibero Americana de Ciências Ambientais, v.11, n.6, p.393-403, 2020. DOI:

http://doi.org/10.6008/CBPC2179-6858.2020.006.0032 


\section{INTRODUÇÃO}

O potencial do mercado cafeeiro no Brasil possui grande expressividade no setor agropecuário. Em 2020, a bienalidade positiva impulsiona recorde na safra de café no país, podendo alcançar a colheita entre 43,2 e 45,98 milhões de sacas beneficiadas de arábica. A área plantada de café arábica corresponde a 81\% da área total com a implementação das lavouras no Brasil, sendo a cultura de maior importância em âmbito nacional (CONAB, 2020).

Dentre as etapas de pós-colheita do grão, o processo de secagem pode ser considerado com um dos mais importantes por afetar diretamente a qualidade de bebida e, consequentemente competitividade no mercado (OLIVEIRA et al., 2020; MOREIRA et al., 2019; SILVIA et al., 2019). Normalmente, a secagem do café é feita por meio do processo natural em terreiros a céu aberto ou secadores mecânicos. No entanto, devido a desvantagens como riscos de contaminação por agentes físicos e biológicos, paralisação do processo em período de chuvas, longos períodos de secagem em terreiros, elevado custo e demanda energética de combustíveis fósseis, que acarretam em risco ao ambiente e a saúde dos trabalhadores e dependência energética em secadores mecânicos, pesquisas vem sendo desenvolvidas a fim de se obter técnicas eficientes com resultado final na qualidade de bebida (OLIVEIRA et al., 2020; MOREIRA et al., 2019). Ainda, tem-se a necessidade de estudos sobre a secagem do café processado de diferentes formas, pois o café processado via seca é mais sensível à secagem mecânica com ar aquecido do que o processado via úmida (ALVES et al., 2017).

A energia solar é uma fonte limpa, sustentável e amplamente acessível, principalmente no Brasil que possui elevado potencial energético a ser explorado seja para geração de energia térmica ou elétrica (MAGALHÃES et al., 2019; OLIVEIRA et al., 2019a). O clima adequado para o uso de energia solar é caracterizado por altos valores de irradiação solar diária, no qual possibilita desenvolvimento de sistemas de secagem solar para produtos agrícolas (ALTOBELLI et al., 2014). Como a radiação solar é abundante no Brasil durante quase todo o ano, a secagem solar dos produtos agrícolas é uma tecnologia promissora (ALVES et al., 2017).

O estudo dos secadores solares para produtos agrícolas tem sido amplamente relatado na literatura nacional e internacional (GÜLER et al., 2020; KHANLARI et al., 2020a; KHANLARI et al., 2020b; MURALI et al., 2020; OLIVEIRA, 2019b; CAMELO et al., 2019; MONTERO et al., 2010). Em especial a secagem do café, o secador solar se apresenta aos produtores rurais como alternativa ao atual método de secagem convencional ao levar em consideração custos, velocidade da secagem e, principalmente, a redução do tempo de processo (MOREIRA et al., 2019; SILVIA et al., 2019; RODRIGUEZ et al., 2018; DEETO et al., 2017). Em adição aos benefícios da utilização de secador solar para o grão, a secagem solar durante períodos com incidência de chuva pode evitar o aumento do tempo de processo em cerca de 17 dias, bem como perda de qualidade do tipo e bebida, mesmo adotando todos os cuidados de movimentação das leiras do café arábica em terreiro de chão (ANDROCIOLI FILHO et al., 2009).

No entanto, ainda há muito o que avançar na utilização dessa tecnologia para o manejo e secagem 
do café. Além disso, a fim de aperfeiçoar e disseminar a secagem solar pesquisas vem sendo desenvolvidas visando a eficiência dos coletores solares que compõem os diferentes tipos secadores existentes (GÜLER et al., 2020; KHANLARY et al., 2020a; KHANLARY et al., 2020b; SILVIA et al., 2019). Os coletores solares têm a finalidade de converter a radiação solar em energia térmica, direcionando o ar com elevada temperatura e reduzida umidade relativa até a câmara de secagem. Khanlary et al. (2020a) utilizaram coletor solar acoplado a câmara de secagem em sistema solar térmico para secagem de raiz de aipo. Khanlary et al. (2020b) secaram amostras de damasco em secador de efeito estufa, com o uso de coletor solar tipo tubo, um sistema alternativo e ecológico. Diante do exposto, objetivou-se avaliar a influência de diferentes condições climáticas na eficiência térmica do coletor solar plano acoplado ao secador híbrido solar elétrico durante a secagem do café arábica.

\section{MATERIAIS E MÉTODOS}

O experimento foi realizado no Laboratório de Eletrificação Rural e Energias Alternativas e Laboratório de Pré-Processamento de Produtos Agrícolas localizados no campus da Universidade Federal Rural do Rio de Janeiro (UFRRJ), Rio de Janeiro - Brasil.

Os frutos da cultivar Catuaí amarelo (IAC-62), provenientes da Fazenda Bom Jardim, localizada no município de Santo Antônio do Amparo, estado de Minas Gerais, foram colhidos manualmente, com teor inicial de água de 1,50 \pm 0,05 decimal base seca (b.s.). Para a determinação do teor de água utilizou-se o método padrão de estufa, $105 \pm 3^{\circ} \mathrm{C}$, durante $24 \mathrm{~h}$, de acordo com Regras para Análise de Sementes (MAPA, 2009).

Os frutos foram separados em lotes de café natural com casca e polpa e teor de água de 1,50 $\pm 0,05$ decimal base seca (b.s.) e café especial compreendendo cereja despolpado a 0,89 $\pm 0,05$ b.s. Durante a etapa de seleção dos lotes de café para a secagem solar foram eliminados os frutos imaturos, deteriorados ou danificados, folhas, pedaços de galhos e outros materiais, com o intuito de se obter um material homogêneo e de melhor qualidade. Após o processo de seleção, o preparo das amostras de café natural foi realizado por via seca e de café especial por via úmida.

\section{Secador Híbrido Solar-Elétrico}

O SHSE (Figura 1) foi composto por coletor solar plano, câmara de secagem e sistema de exaustão acionado por energia elétrica convencional e/ou fotovoltaica com seguidor solar (Figura 1a).

O CSP plano foi construído em caixa metálica de alumínio no formato retangular $(0,68 \times 3,00 \times 0,14$ m largura $x$ comprimento $x$ altura) e acoplado na parte inferior da câmara de secagem. $O$ dimensionamento do CSP adotado seguiu que para cada metro cúbico da câmara de secagem é necessária uma área de $8 \mathrm{~m}^{2}$ de CSP, formando a proporção de $1 \mathrm{~m}^{3}: 8 \mathrm{~m}^{2}$, conforme adotado por Oliveira (2019b). O interior do CSP foi composto, em sequência, por isopor fixado nas laterais e no fundo da caixa, superfície absorvedora de radiação e cobertura de vidro transparente liso $(0,004 \mathrm{~m})$ fixado na caixa metálica com o uso de silicone. A superfície absorvedora da radiação solar foi composta por estrutura de alumínio sanfonada em perfil $(0,10 \mathrm{x}$ 
0,08 m base $x$ altura) pintada de preto fosco. O CSP foi acoplado a câmara de secagem.
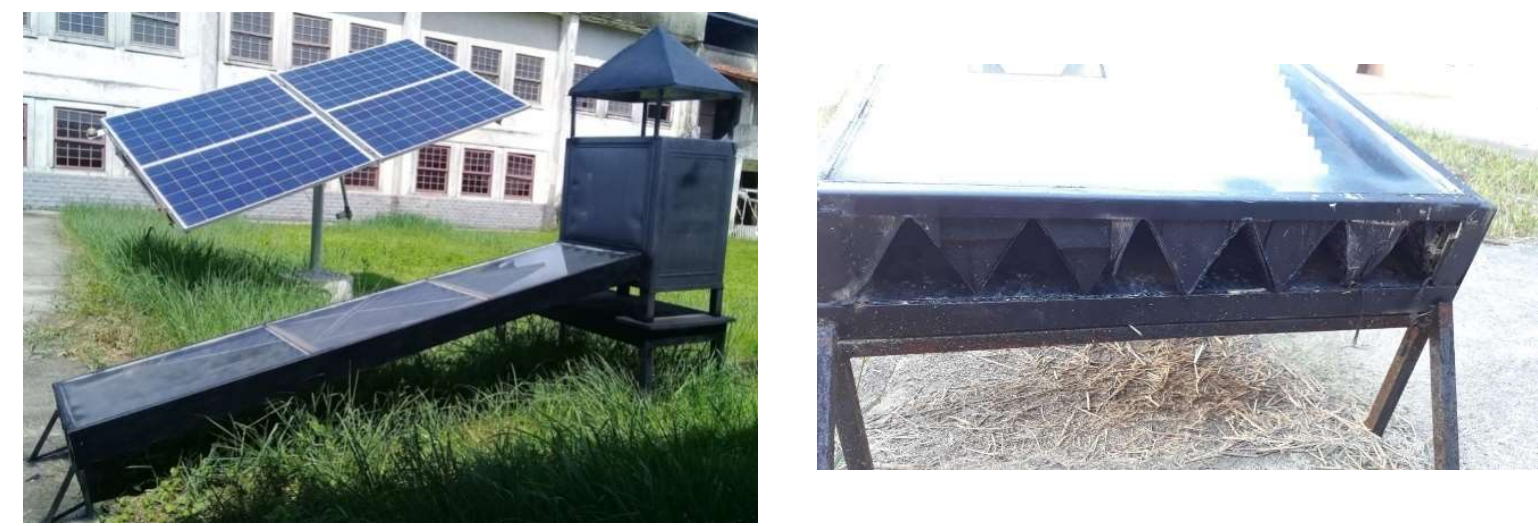

Figura 1: Secador híbrido solar-elétrico a) coletor solar plano b) entrada do ar ambiente.

O circuito do fluido térmico no CSP foi percorrido pelo ar ambiente através dos seis canais em inferiores da superfície absorvedora para adquirir energia térmica até a câmara de secagem. Os canais superiores da superfície absorvedora foram vedados a fim da passagem de ar ambiente ser apenas pela seção triangular inferior (Figura 1b). A saída da massa de ar ocorreu no local de acoplamento entre o CSP e a câmara de secagem.

A câmara de secagem foi construída em estrutura cúbica $(1,79 \times 1,01 \times 0,85 \mathrm{~m}$ largura $\times$ altura $\mathrm{x}$ profundidade) e volume de 1,52 $\mathrm{m}^{3}$, pintada de preto fosco. No interior consta três bandejas contendo nove cestas removíveis para contenção de produtos agrícolas, distanciadas igualmente entre si. As cestas possuem fundo telado para permitir a passagem do ar de secagem através dos lotes de café natural e especial. Na parte superior da câmara foi instalado um exaustor acionado por energia convencional da rede elétrica, com potência de $144 \mathrm{~W}$, a fim de garantir a convecção forçada do ar de secagem em seu interior. No exaustor acoplou-se um dimmer na forma de potenciômetro (controle de velocidade), o qual permitiu controlar a rotação do aparelho mantendo a velocidade média de $0,92 \pm 0,32 \mathrm{~m} \mathrm{~s}^{-1}$.

\section{Monitoramento dos parâmetros da secagem solar}

Ao longo do processo de secagem, o CSP do SHSE foi monitorado quanto à temperatura $\left(T_{\text {arsec }}\right)$ em

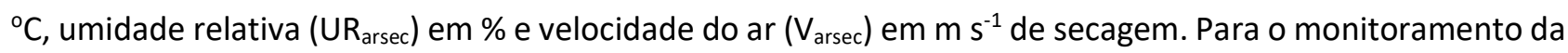
$T_{\text {arsec }}$ foram utilizados termopares conectados a um milivoltímetro com precisão $\pm 0,1{ }^{\circ} \mathrm{C}$. $A$ UR arsec foi mensurada por meio de um termo-higrômetro modelo MTH-1380. A $\mathrm{V}_{\text {arsec }}$ foi monitorada com o auxílio de um termo-anemômetro digital marca Minipa, modelo MDA II. A coleta dos parâmetros foi realizada em períodos regulares a cada hora.

Os dados de temperatura ( $\left(\mathrm{T}_{\text {aramb}}\right.$ ) em ${ }^{\circ} \mathrm{C}$, umidade relativa (UR aramb) em \%, irradiação solar (I) em W $\mathrm{m}^{-2}$ e índice pluviométrico (IP) em $\mathrm{mm}$ referentes ao período da secagem solar foram obtidos com o Instituto Nacional de Meteorologia (INMET), provenientes da estação meteorológica automática de Ecologia Agrícola, localizada no município de Seropédica, Rio de Janeiro, Brasil. Esta estação meteorológica encontra-se situada a 1,5 km de distância dos Laboratórios utilizados da UFRRJ. 


\section{Procedimento adotado para secagem do café}

As cestas removíveis de cada bandeja foram preenchidas completamente com amostras de café natural e especial formando uma camada delgada de 0,03 m. Em seguida, as bandejas foram alocadas na câmara de secagem para iniciar o processo. As cestas foram pesadas, a cada uma hora, em balança semi analítica de precisão de 0,1g da marca Marte AD3300, identificadas e dispostas no interior da câmara de secagem, em ordem aleatória. Encerou-se o processo de secagem solar quando o produto atingiu o teor de água de aproximadamente 0,13 $\pm 0,05$ b.s.

A secagem das amostras foi realizada em quatro dias seguidos, entre 12 a 15 de junho de 2018 , no período de 08:00 às 17:00 h, com período efetivo de secagem de $36 \mathrm{~h}$. Durante o período noturno, como não há efeito da radiação solar considerou-se como intermitência de 15 h entre 17:00 e 8:00 h. No período de intermitência, as aberturas do CSP e do exaustor na câmara foram vedadas, a fim de evitar a entrada de ar ambiente úmido no período noturno na câmara de secagem. Os dois primeiros dias de secagem solar foi considerado como período ensolarado (PS) e os subsequentes como período com incidência de chuva (PC).

\section{Eficiência térmica do coletor solar plano}

A eficiência do CSP foi determinada em função da razão entre a energia útil fornecida e a energia solar incidente ao longo do período de secagem solar (Equação 1).

$$
\eta_{c}=\frac{E_{u}}{E_{i}}=\frac{\int P_{u c o l} d t}{A_{d} \int I_{t} d t}=\frac{P_{u c o l}}{P_{i}}=\frac{\dot{m} \times c_{p} \times\left(T_{o}-T_{i}\right)}{I_{t} \times A_{d}}
$$

Em que,

$\begin{aligned} \eta_{c s p} & - \\ E_{u} & - \\ E_{i} & - \\ P_{u c o l} & - \\ A_{d} & - \\ I_{t} & - \\ P_{i} & - \\ \dot{m} & - \\ c_{p} & - \\ T_{0} & - \\ T_{i} & \end{aligned}$

Eficiência térmica do coletor solar plano;

Energia útil fornecida pelo coletor solar plano ao longo do período de secagem t; Energia solar incidente no coletor solar plano ao longo do período de secagem $t$;

Ganho de energia útil, W; Área superficial do coletor solar plano exposta a radiação solar, $\mathrm{m}^{2}$; Irradiância na superfície inclinada, $\mathrm{W} \mathrm{m}^{-2}$; Potencial relacionado à energia solar, $\mathrm{W}$; Vazão mássica do ar, $\mathrm{kg} \mathrm{s}^{-1}$; Calor específico do ar, $\mathrm{J}\left(\mathrm{kg}^{\circ} \mathrm{C}\right)^{-1}$; Temperatura externa do coletor solar plano, ${ }^{\circ} \mathrm{C}$; e Temperatura interna do coletor solar plano, ${ }^{\circ} \mathrm{C}$.

Para o cálculo da m e a massa específica do ar de entrada no CSP foi adotada a Equação 2 e Equação 3, respectivamente (MONTERO et al., 2010).

$$
\dot{m}=\rho \times A_{c} \times v_{m}
$$

Em que,

$\rho-$

$A_{C}-$

$v_{\mathrm{m}}-$
Massa específica do ar de entrada no coletor solar plano, $\mathrm{kg} \mathrm{m}^{-3}$;

Área transversal do coletor solar plano; $\mathrm{m}^{2}$; e Velocidade média do ar na entrada do coletor solar plano, $\mathrm{m} \mathrm{s}^{-1}$.

$$
\rho=\frac{353,44}{T_{i}+273,15}
$$

Conforme o trabalho desenvolvido por Silveira (2016), para a avaliação da eficiência do CSP foi levado 
em consideração que o isolamento do sistema não permite vazamento de ar. $\mathrm{O}$ ar no interior do CSP comporta-se como um gás ideal à pressão constante, desprezível a transmitância-absorbância entre o vidro e a placa absorvedora. Considerou-se a irradiação medida em uma superfície plana (estação meteorológica) igual a superfície inclinada. Para o cálculo da eficiência do CSP foi adotado o calor específico do ar de $1.006 \mathrm{~J}$ $\left(\mathrm{kg}^{\circ} \mathrm{C}\right)^{-1}$. No presente estudo considerou-se a eficiência do CSP inferior a $100 \%$, conforme no trabalho desenvolvido por Altobelli et al. (2014) e Dina et al. (2015).

\section{RESULTADOS E DISCUSSÃO}

Durante o processo de secagem solar do café, a temperatura média do ar ambiente foi de $23,1{ }^{\circ} \mathrm{C}$, sendo no PS (dois primeiros dias de secagem solar) de $26,4^{\circ} \mathrm{C}$ e PC de $19,8{ }^{\circ} \mathrm{C}$. Já a umidade relativa média do ar ambiente, PS e PC foi de 76,0, 62,0 e 89,9\%, respectivamente. No PS ocorreram maiores temperaturas (Figura 2a) e menores valores de umidade relativa (Figura 2b) do ar ambiente quando comparado ao PC.
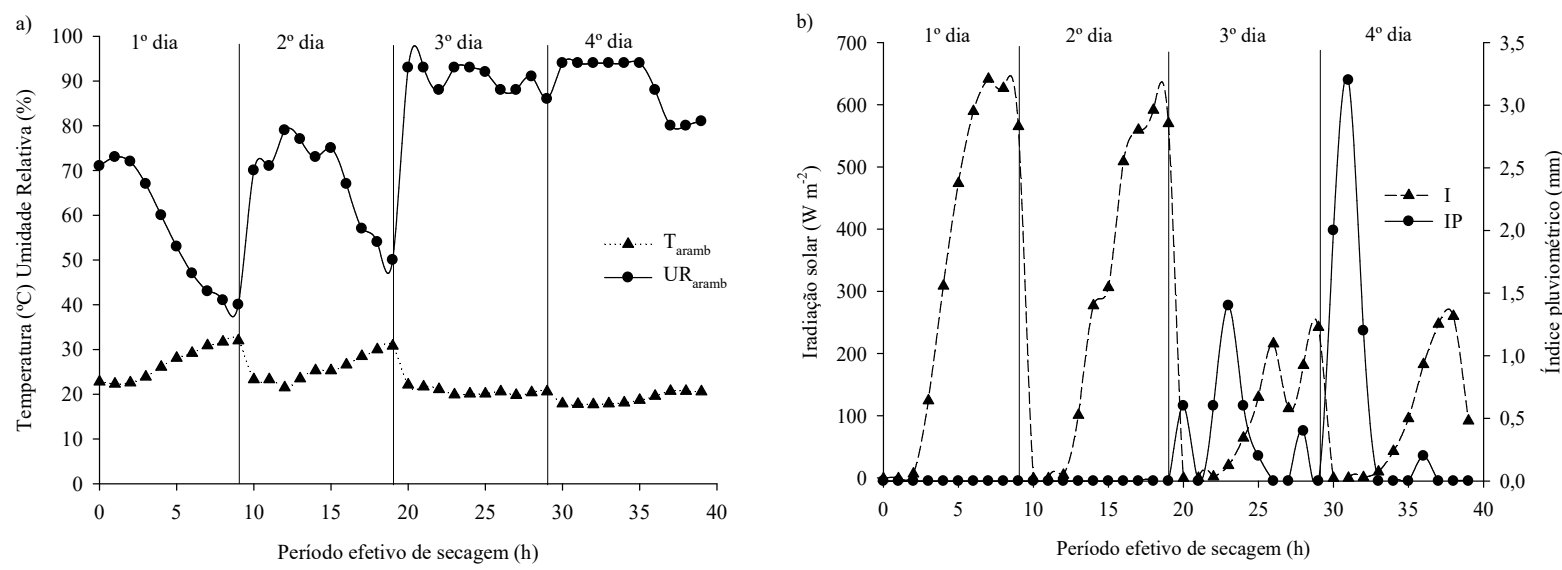

Figura 2: Parâmetros coletados no INMET a) Temperatura e Umidade Relativa e b) Irradiação Solar e Índice Pluviométrico no período de 8:00 às 17:00 h.

Associado aos parâmetros de temperatura e umidade relativa do ar ambiente, a irradiação solar média foi de 210,9 W m-2 ao longo de todo o período efetivo de secagem solar, com média de 312,5 W m-2 no PS e de 109,3 W m-2 no PC. Isto é, houve redução de 65\% na indicência da irradiação solar com a variação das condições climáticas. O período entre 8:00 e 10:00 h foi caracterizado com baixa incidência de irradiação solar, apresentando média de 0,7 W m-2. A partir desse momento, que compreende de 11:00 às 17:00 h, verifica-se elevação da irradiação solar apresentando média de $301,0 \mathrm{~W} \mathrm{m-2}$. No que tange o índice pluviométrico, houve ocorrência de chuva apenas nos dois últimos dias, sendo o índice pluviométrico total de $10,4 \mathrm{~mm}$. Moreira et al. (2019) relatou irradiação solar média em torno de $598{\mathrm{~W} \mathrm{~m}{ }^{2}}^{2}$ e condições climáticas no primeiro dia de sol e nos 3 dias sequentes nublado durante a secagem do café em secador solar direto.

Apresenta-se na Figura 3 a temperatura e UR no CSP, com valores médios de $25,8{ }^{\circ} \mathrm{C}$ e $77,7 \%$ na entrada e $29,9{ }^{\circ} \mathrm{C}$ e $73,3 \%$ na saída, respectivamente, ao longo do período efetivo de secagem solar. Ao comparar os parâmetros do ar de secagem com o ar ambiente, a temperatura média na entrada e saída do CSP foi superior 11 e $20 \%$. Já no que tange a UR média, tem-se que na entrada do CSP houve aumento de $2 \%$ 
e na saída redução de $4 \%$ ao comparar com relação ao ar ambiente. A diferença dos parâmetros de temperatura e UR na entrada do CSP quando comparado com o ar ambiente provavelmente pode ser oriunda da proximidade da base inferior do CSP com o chão (concreto e gramado).

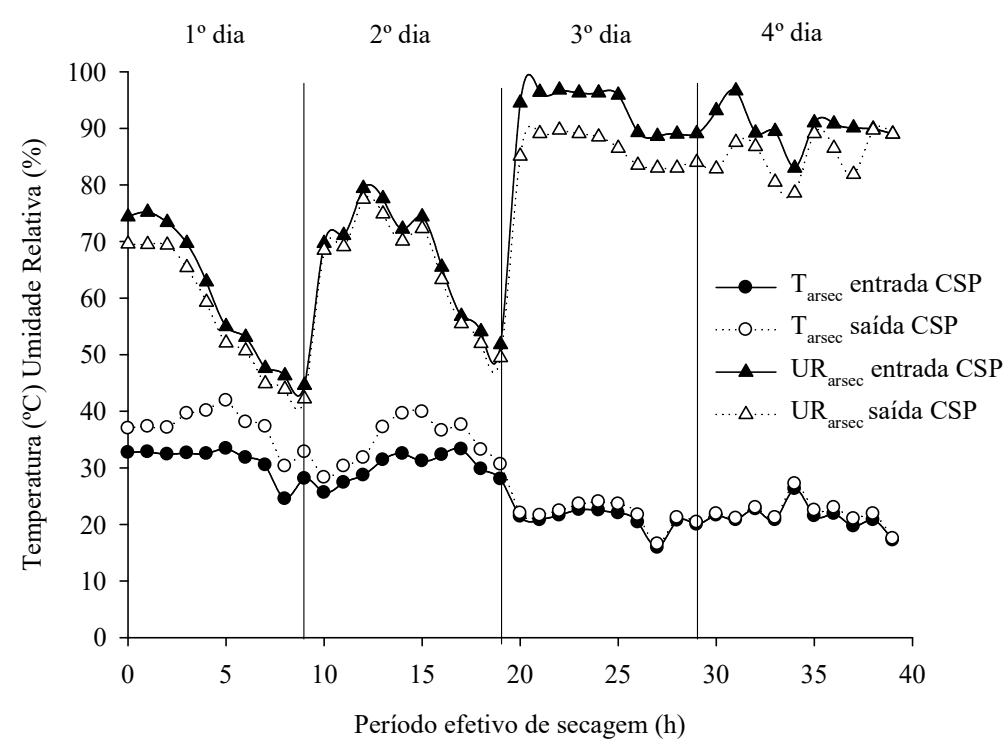

Figura 3: Variação da temperatura $(\mathrm{oC})$ e umidade relativa (\%) do ar de secagem e ambiente longo do período de secagem.

Os valores médios de temperatura e UR do ar de secagem na entrada e saída no CSP foi, respectivamente de, 30,6 e 35,8 oC e 63,7 e $61,0 \%$ no PS e de 21,1 e 21,9 oC e 91,7 e $85,7 \%$ no PC. Como esperado, observa-se maior temperatura e menor umidade relativa do ar de secagem na saída quando comparado com a entrada do coletor solar plano, independente das condições climáticas do período de secagem (Figura 3).

A maior temperatura com a respectiva umidade relativa média atingida na saída do coletor solar plano ocorreu após 5 h (13:00 h) de secagem solar do primeiro dia do PS, sendo de 41,9 oC e 52,1\%. Nesse mesmo tempo de secagem solar a temperatura com sua respectiva umidade relativa na entrada do CSP foi de 33,4 oC e $55,0 \%$, isto é, um incremento de 8,5 oC e redução de $2,9 \%$. A menor temperatura na saída do coletor solar plano ocorreu no PC após 27 h de secagem solar (15:00 h), sendo de 16,5 oC (83\% de UR) com correspondente valores na entrada do CSP de 15,9 oC e $88,6 \%$.

A temperatura do ar de secagem de produtos agrícolas deve estar dentro de determinada faixa afim de não prejudicar a qualidade final do produto seco (KHANLARI et al., 2020a; ALVES et al., 2017). No processo de secagem do café, é necessário manter a temperatura abaixo do valor máximo recomendado (55 oC) para preservar suas características (BOLIGON et al., 2009). Ainda, a secagem pode ser realizada a baixa temperatura com o ar aquecido no máximo a 10 oC acima da temperatura ambiente (MOREIRA et al., 2019). Pesquisas foram desenvolvidas em forno com circulação de ar forçada a 40 oC (BOTELHO et al., 2016) e $45 \pm$ 2 oC (MUSEMBI et al., 2016), fornalha de fogo indireto com variação entre 10 a 50 oC (OLIVEIRA et al., 2020) e secador de camada fixa nas temperaturas de 35, 40 e 45 oC (ISQUIERDO et al., 2013). A temperatura do ar de secagem influencia na taxa de secagem e, por consequência, na qualidade sensorial do café despolpado. A secagem do café em secador de leito fixo na temperatura de 40 oC apresentou uma correlação positiva 
entre o tempo de secagem e a qualidade fisiológica e sensorial (ALVES et al., 2017). Em secador solar direto a temperatura com valor médio de $50^{\circ} \mathrm{C}$, o café apresentou defeitos nos grãos e fermentação, porém pela análise de bebida obteve-se classificação tipo dura. Assim, pode-se verificar que a faixa de temperatura atingida no coletor solar plano do secador híbrido solar elétrico está dentro da faixa aceitável para a secagem do café.

Conforme reportado na literatura a diferença entre a temperatura na saída e entrada do coletor solar é importante para avaliar a eficiência do coletor solar (GÜLER et al., 2020; KHANLARI et al., 2020b). Verificase na Figura 3 que a maior diferença entre os parâmetros monitorados na entrada e saída ocorreu com a temperatura no PS $(8,7$ oC) e UR no PC (10,3\%). Valores superiores foram reportados por Güler et al. (2020), sendo de 10,49 e 12,78 oC para coletor solar plano com passagem dupla e passagem dupla com modificação do absorvente de malha, respectivamente. No entanto, no trabalho desenvolvido por esses autores a diferença de temperatura entre o ar de saída e entrada foi obtida em coletor solar plano com sistemas para aumentar a eficiência térmica.

Assim como adotado por Dina et al. (2015) ao estudar a secagem solar de sementes de cacau, não foi considerado o período de baixa incidência de radiação solar, uma vez que os valores de eficiência são superiores a $100 \%$. Para o café no SHSE, eficiência térmica superior a 100\% ocorreu no período de 8:00 às 10:00 h nos quatro dias de secagem solar.

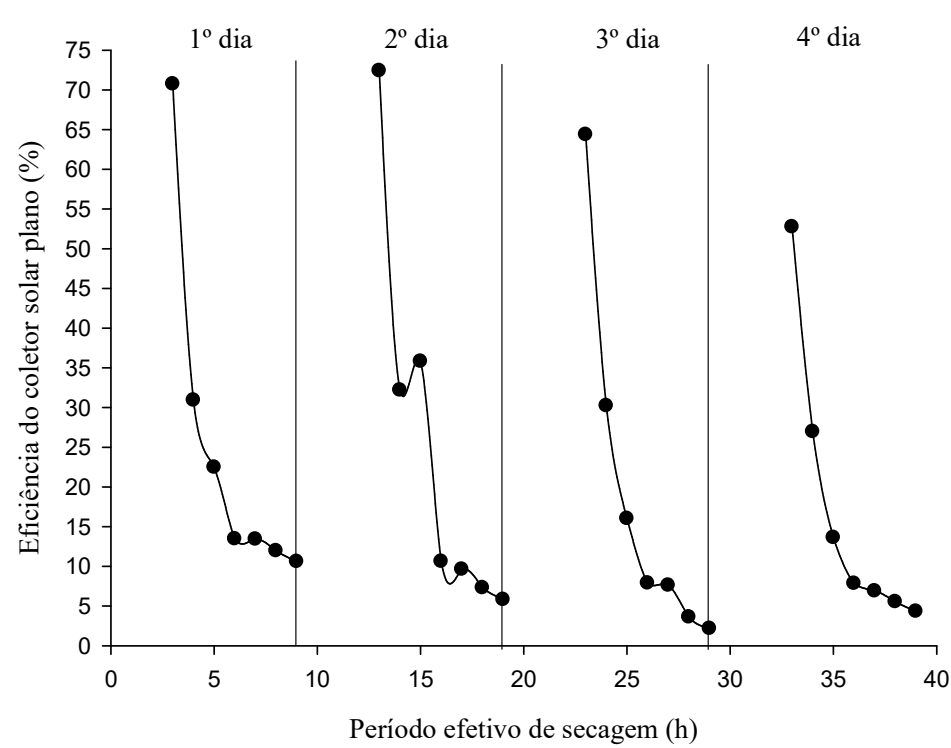

Figura 4: Eficiência do coletor solar plano.

Pode-se observar na Figura 4, maiores valores da eficiência térmica do CSP no período ensolarado, seguido por decréscimo nos dias com incidência de chuva. A eficiência térmica média do CSP no primeiro, segundo, terceiro e quarto dia foi, respectivamente, de 24,8, 24,8, 18,8 e 16,8\%, com eficiência térmica global de $21,3 \%$. A diferença apresentada pelo parâmetro temperatura na entrada e saída do CSP (Figura 3) ocasionada pelas condições ambientais (radiação solar e índice pluviométrico) referente ao período ensolarado e com incidência de chuvas (Figura 2) refletiu na eficiência térmica do CSP (Figura 4).

Ainda, observa-se na Figura 4 que em todos os dias da secagem solar o pico da eficiência térmica do 
coletor solar ocorreu às 11:00 h, seguido de um decréscimo, independente de período ensolarado ou chuvoso. A eficiência média máxima obtida às $11: 00$ h foi de 71,6 e $58,6 \%$ no período ensolarado e de chuva, respectivamente.

Oliveira (2019b) relataram que a eficiência média máxima e a global do coletor solar plano foi de 59 e 26\% para a secagem da manga, respectivamente. O valor médio de eficiência máxima do coletor solar plano do SHSE no período chuvoso foi semelhante, enquanto a média global $4,7 \%$ inferior ao encontrado por Oliveira (2019b). No entanto, a máxima eficiência média obtida ocorreu às 14:00 h para a temperatura de saída e radiação global de 59,0 oC e 361 W m-2, respectivamente (OLIVEIRA, 2019b). Para a secagem solar da banana em secador contendo coletor solar plano obteve-se eficiência global de 31,5\%, em condições de temperatura da entrada e saída e radiação global média de 42 e 62 oC e $724 \mathrm{~W}$ m-2, respectivamente (LINGAYAT et al., 2017). A eficiência térmica global superior ao relatado no presente trabalho, pode ser justificado pelos elevados valores de irradiação solar e da temperatura de entrada e saída do coletor solar. Segundo Lingayat et al. (2017), a temperatura do ar de secagem é o fator mais importante e eficaz durante o processo.

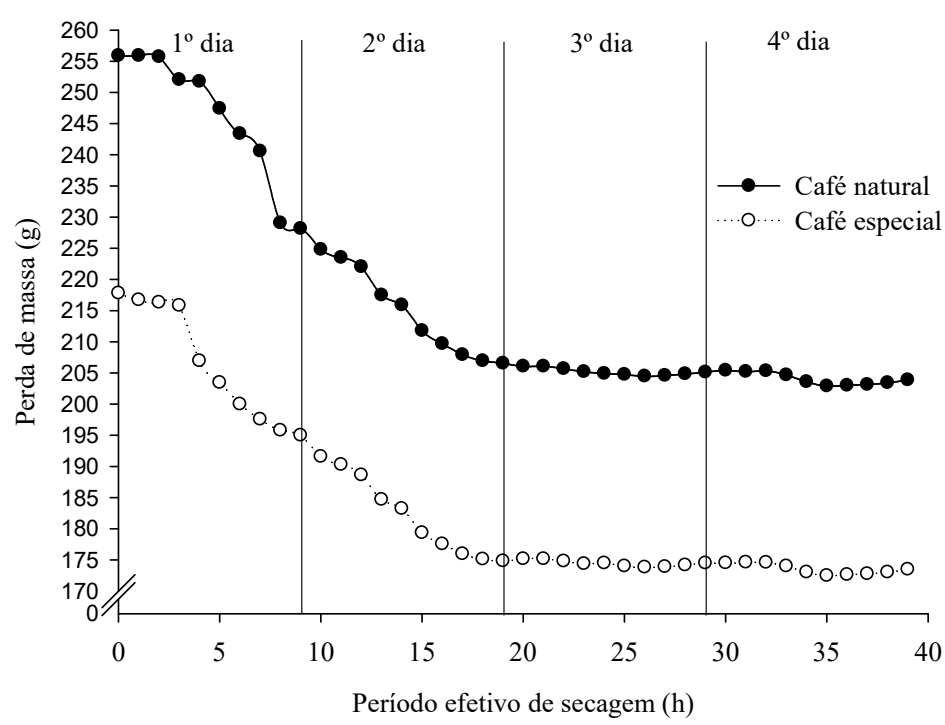

Figura 5: Perda de peso durante os dias de secagem a) café natural e b) café especial.

No geral, a massa de grãos despolpado e natural reduziu, respectivamente, 27,4 e $34,2 \%$ devido à perda de água. No que tange ao efeito do período de intermitência, observa-se que o produto não absorveu umidade conforme relatado por Camelo et al. (2019) na secagem solar da banana (Figura 5). Ainda, pode-se observar que a massa inicial do grão despolpado foi superior quando comparado com o natural. Justifica-se essa diferença de massa inicial devido ao tratamento via úmida utilizado para o despolpamento. No entanto, verifica-se maior perda de massa nos dois primeiros dias tanto no grão despolpado quanto no natural. A maior velocidade de retirada de água nos dois primeiros dias é decorrente da eliminação inicial da água livre de superfície no grão. A rápida taxa de secagem inicial é decorrente do maior gradiente entre teor de água do produto e a umidade relativa do ar seco e da menor interação entre as moléculas de água e o produto. A taxa de secagem torna-se lenta à medida que o gradiente entre esses fatores é reduzido (MOREIRA et al., 
2019; LINGAYAT et al., 2017).

Verifica-se na Figura 5 a estabilização na perda de massa no início do período chuvoso (19 h de secagem), assim como a não interferência na secagem do café como ocorre comumente em processos convencionais. Dessa forma, pode-se considerar que no último dia o produto atingiu o equilíbrio higroscópico com o ambiente. Em terreiro de chão e suspenso no período chuvoso há retardo na secagem do café acarretando aumento do período, e provável interferência na qualidade final do produto. Silvia et al. (2019) relataram que a secagem do café em secador solar híbrido é muito mais rápida do que a secagem natural, sendo cerca de 60, 52 e $36 \mathrm{~h}$ para espessura de camada dos frutos de 15, 10 e $5 \mathrm{~cm}$, respectivamente. Moreira et al. (2019) alcançou a estabilização durante a secagem do café em secador solar direto após, aproximadamente, $27 \mathrm{~h}$ de secagem, comprovando a eficiência do secador solar indireto.

\section{CONCLUSÕES}

O comportamento da diferença de temperatura e umidade relativa foi decorrente do período ensolarado nos dois primeiros dias com elevada irradiação solar, seguidos de incidência de chuva. No entanto, a temperatura atingida na saída do coletor solar plano acoplado ao secador híbrido solar elétrico é ideal para a secagem do café despolpado e natural. O SHSE composto pelo coletor solar plano foi eficiente na secagem dos frutos de café tanto em períodos ensolarados quanto chuvosos, independentemente de ser café despolpado ou natural.

O secador híbrido solar elétrico podem vir a ser uma alternativa aos atuais métodos de secagem natural convencional do café, visando a obtenção de produtos diferenciados no mercado por adotar meios ambientalmente correto.

\section{REFERÊNCIAS}

ALTOBELLI, F.; CONDORÍ, M.; DURAN, G.; MARTINEZ, C.. Solar dryer efficiency considering the total drying potential. Application of this potential as a resource indicator in northwestern Argentina. Solar Energy, v.105, p.742-759, 2014. DOI: http://dx.doi.org/10.1016/j.solener.2014.04.029

ALVES, G. E.; BORÉM, F. M.; ISQUIERDO, E. P.; SIQUEIRA, V. C.; CIRILLO, M. A.; PINTO, A. C. F.. Physiological and sensorial quality of Arabica coffee subjected to different temperatures and drying airflows. Acta Scientiarum Agronomy, Maringá, v.39, n.2, p.225-233, 2017. DOI:

http://doi.org/10.4025/actasciagron.v39i2.31065

ANDROCIOLI FILHO, A.; CARNEIRO FILHO, F.; LIMA, F. B.; GAIR, R.; HERNADEZ, J. C.; AZEVEDO, J. A.; FANTIN, D.; MORAIS, H.; CARAMORI, P. H.. Simulação de períodos de chuva no terreiro de secagem e efeito no tipo e bebida do café. In: SIMPÓSIO DE PESQUISA DOS CAFÉS DO BRASIL, 6. Anais. 2009.

BOLIGON, S.; BENMOUSSA, H.; BOUCHEKIMA, B.; MENNOUCHE, D.; BOUGUETTAIA, H.; BECHKI, D.. Crop drying by indirect active hybrid solar: Electrical dryer in the eastern Algerian Septentrional Sahara. Solar Energy, v.83, p.2223-
2232, 2009. DOI:

http://doi.org10.1016/j.solener.2009.09.006

BOTELHO, F. M.; CORRÊA, P. C.; BOTELHO, S. C. C.; VARGASELÍAS, G. A.; ALMEIDA, M. D. S. D.; OLIVEIRA, G. H. H.. Propriedades físicas de frutos de café robusta durante a secagem: determinação e modelagem. Coffee Science, Lavras, v.11, n.1, p.65-75, 2016.

CAMELO, R. S. S.; PAES, J. L.; BRÁS, M. R. S.; BRUGGIANESI, G. GUIMARÃES, C. L.. Kinetics drying of silver banana (Musa spp.) in hybrid dryer. Revista Ciência Agronômica, v.50, n.3, p.353-360, 2019. DOI: https://doi.org/10.5935/18066690.20190042

BRASIL. Regras para análise de sementes. Brasília: MAPA, 2009.

CONAB. Companhia Nacional de Abastecimento.

Acompanhamento de safra brasileira de café: Safra 2020, Primeiro levantamento. Brasília: CONAB, 2020.

DEETO, S.; THEPA, S.; MONYAKUL, V.; SONGPRAKORP, R.. The experimental new hybrid solar dryer and hot water storage system of thin layer coffee bean dehumidification. 
Renewable Energy, v.115, n.1, p.954-968, 2017. DOI: https://doi.org/10.1016/i.renene.2017.09.009

DINA, S. F.; AMBARITA, H.; NAPITUPULU, F. H.; KAWAI, H.. Study on effectiveness of continuous solar dryer integrated with desiccant thermal storage for drying cocoa beans. Case Studies in Thermal Engineering, v.5, n.1, p.32-40, 2015. DOI: http://dx.doi.org/10.1016/j.csite.2014.11.003

GÜLER, H. O.; SÖZEN, A.; TUNCER, A. D.; AFSHARI, F.; KHANLARI, A.; SIRIN, C.; GUNGOR, A.. Experimental and CFD survey of indirect solar dryer modified with low-cost iron mesh. Solar Energy, v.197, n.1, p.71-384, 2020. DOI: https://doi.org/10.1016/j.solener.2020.01.021

ISQUIERDO, E. P.; BORÉM, F. M.; ANDRADE, E. T.; CORRÊA, J. L. G.; OLIVEIRA, P. D.; ALVES, G. E.. Drying kinetics and quality of natural coffee. Transactions of the ASABE, v.56, n.3, p.1003-1010, 2013. DOI: http://dx.doi.org/10.13031/trans.56.9794

KHANLARI, A.; SOZEN, A.; SIRIN, C.; TUNCER, A. D.; GUNGOR, A.. Performance enhancement of a greenhouse dryer: Analysis of a cost-effective alternative solar air heater. Journal of Cleaner Production, v.251, p.1-30, 2020a. DOI: https://doi.org/10.1016/j.jclepro.2019.119672

KHANLARI, A.; GULER, H. O.; TUNCER, A. D.; SIRIN, C.; BILGE, Y. C.; YILMAZ, Y.; GUNGOR, A.. Experimental and numerical study of the effect of integrating plusshaped perforated baffles to solar air collector in drying application. Renewable

Energy, v.145, n.1, p.1677-1692, 2020b. DOI:

https://doi.org/10.1016/j.renene.2019.07.076

LINGAYAT, A.; CHANDRAMOHAN V. P.; RAJU, V. R. K.. Design Development and performance of indirect type solar dryer for banana drying. Energy Procedia, v.109, p.409-416, 2017. DOI: https://doi.org/10.1016/i.egypro.2017.03.041

MAGALHÃES, M. A.; SANTOS, F. G. C.; LUZ, E. G.; NOGUEIRA, M. C. J. A.; SANTOS, F. M. M.. Análise do potencial da utilização de energia solar em Cuiabá/MT. Revista Ibero Americana de Ciências Ambientais, v.10, n.3, p.114-123, 2019. DOI: http://doi.org/10.6008/CBPC21796858.2019.003.0011

MONTERO, I.; BLANCO, J.; MIRANDA, T.; ROJASA, S.; CELMA A. R.. Design, construction and performance testing of a solar dryer for agroindustrial by-products. Energy

Conversionand Management, v.51, n.7, p.1510-1521, 2010. DOI: https://doi.org/10.1016/i.enconman.2010.02.009

MOREIRA, D. H. F.; FREITAS, F. F.; LANDY, C. C. R.; CHARBEL, A. L. T.. Analysis of coffee drying in direct passive solar dryer. Brazilian Journal of Development, Curitiba, v.5, n.9, p.16556-16573, 2019. DOI: http://doi.org/10.34117/bjdv5n9-200

MURALI, S.; AMULYA, P. R.; ALFIYA, P. V.; DELFIYA, D. S. A.; SAMUEL, M. P.. Design and Performance Evaluation of Solar: LPG Hybrid Dryer for Drying of Shrimps. Renewable Energy, v.147, n.1, p.2417-2428, 2020. DOI: https://doi.org/10.1016/j.renene.2019.10.002

MUSEMBI, M. N.; KIPTOO, K. S.; YUICHI, N.. Design and analysis of solar dryer for mid-latitude region. Energy Procedia, v.100, p.98-110, 2016. DOI: http://doi.org/10.1016/j.egypro.2016.10.145

OLIVEIRA, I. C.; GUERRA, M. I. S.; VIEIRA, R. G.. Uma revisão sobre a tecnologia solar híbrida fotovoltaica e térmica no Brasil e no mundo. Revista de Engenharia e Tecnologia, v.11, n.3, p.181-205, 2019a.

OLIVEIRA, L. C. T. G.. Evaluation of the efficiency of the flat solar collector coupled in hybrid dryer. In: PAES, J. L.; GUIMARÃES, C. L.; CAMELO, R. S. S.; MISQUITA, Í. S.; LOVISI, T. A. P.. Energia Solar e Eólica. Ponta Grossa: Atena, 2019b. p.194-211.

OLIVEIRA, F. S.; ANDRADE, E. T.; MOREIRA, K. S.; SOUZA, S. M. C.; BORÉM, F. M.. Fixed bed dryer: an adaptation to improve drying of natural coffee in Brazil. Society and Development, v.9, n.7, p.01-32, 2020. DOI: http://dx.doi.org/10.33448/rsd-v9i7.3197

RODRIGUEZ, A. C. Z.; GAMEZ, M. R.; FAURE, L. G.. Design, construction, and energy of sustainable solar dryers in Jipijapa Canton. International Journal of Physical Sciences and Engineering, v.2, n.2, p.88-100, 2018. DOI: https://doi.org/10.29332/ijpse.v2n2.170

SILVIA, E.; YUWANA, Y.; BOSMAN, S.. Performance of modified hybrid solar dryer on the drying process of Robusta cherry coffee. Journal Agroindustrial, v.9, n.2, p.94-101, 2019. DOI: http://doi.org/10.31186/j.agroind.9.2.94-101

A CBPC - Companhia Brasileira de Produção Científica (CNPJ: 11.221.422/0001-03) detém os direitos materiais desta publicação. Os direitos referem-se à publicação do trabalho em qualquer parte do mundo, incluindo os direitos às renovações, expansões e disseminações da contribuição, bem como outros direitos subsidiários. Todos os trabalhos publicados eletronicamente poderão posteriormente ser publicados em coletâneas impressas sob coordenação da Sustenere Publishing, da Companhia Brasileira de Produção Científica e seus parceiros autorizados. Os (as) autores (as) preservam os direitos autorais, mas não têm permissão para a publicação da contribuição em outro meio, impresso ou digital, em português ou em tradução. 